\title{
Quantifying the wind dispersal of Culicoides species in Greece and Bulgaria
}

E. Ducheyne ${ }^{1}$, R. De Deken², S. Bécu², B. Codina ${ }^{3}$, K. Nomikou ${ }^{4}$, O. Mangana-Vougiaki ${ }^{4}$, G. Georgiev ${ }^{5}$, B.V. Purse ${ }^{6}$, G. Hendrickx ${ }^{1}$

${ }^{1}$ Avia-GIS, Risschotlei 33, 2980 Zoersel, Belgium; ${ }^{2}$ Department of Veterinary Sciences, Prince Leopold Institute of Tropical Medicine, Nationalestraat 155, 2000 Antwerpen, Belgium; ${ }^{3}$ Department of Astronomy and Meteorology, Faculty of Physics, Martí i Franquès 1, 08028 Barcelona, Spain; ${ }^{4}$ Institute of Infectious and Parasitic Diseases, Virus Laboratory, 25 Neapoleos Str., 15310 Athens, Greece; ${ }^{5}$ Central Veterinary Research Institute, P. Slaveikov Blvd 15, 1606 Sofia, Bulgaria; 'Spatial Ecology and Epidemiology Group, Department of Zoology, South Parks Rd., Oxford OX1 3PS, UK

\begin{abstract}
This paper tests the hypothesis that Culicoides (Diptera: Ceratopogonidae) species can be propagated by wind over long distances. Movement patterns of midges were inferred indirectly from patterns of the spread of bluetongue outbreaks between farms (using outbreak data from 1999-2001 for Greece, Bulgaria and Turkey) and then matched to concurrent wind patterns. The general methodology was to determine wind trajectories to and from each outbreak site based on the horizontal and vertical wind components of the European ReAnalysis-40 (ERA-40) dataset from the European centre for medium-range weather forecast (ECMWF). Forward trajectories (downwind or where the windvectors pointed to) and backward trajectories (upwind or where the wind-vectors originated from) were calculated for each outbreak for the period from one week before to one week after it had been recorded. These wind trajectories were then compared with the general outbreak patterns taking into consideration the different serotypes involved. It was found that the wind trajectories could be matched to the temporal distribution of the outbreak cases. Furthermore, the spread of the infected vector via the calculated wind trajectories was corroborated by molecular evidence. The conclusion is that the methodology presented is appropriate for quantifying the risk of spread of infected Culicoides midges by wind and that this approach could form an important component of a regional early-warning system for bluetongue.
\end{abstract}

Keywords: wind-borne spread, insect vectors of diseas, Culicoides, bluetongue, Mediterranean.

\section{Introduction}

Whilst diseases move more rapidly around the world due to increasing trade and travel, dispersal by insect vectors has also been implicated as a way of introducing pathogens into new areas. The impact of this potential route of introduction must not be underestimated. For example, Ritchie and Rochester

\footnotetext{
Corresponding author:

Guy Hendrickx

Avia-GIS

Risschotlei 33

2980 Zoersel, Belgium

Tel./Fax +32 34582979

E-mail: ghendrickx@avia-gis.be
}

(2001) showed that the Japanese encephalitis virus was introduced into Australia by wind-blown Culex spp., while Baker et al. (1990) demonstrated the reinvasion of cleared land in West Africa by Simulium spp. that had spread by monsoonal winds during the rainy season. Therefore, analysing the process of arrival, establishment and consequent spread of these vectors is very important.

Bluetongue is an arboviral disease, part of the former "Office International des Epizooties" (OIE) List A disease group that causes high mortality, mainly in certain breeds of sheep but also in other domestic and wild ruminants. The bluetongue virus is transmitted between ruminant hosts almost entirely by the bites of Culicoides (Diptera: 
Ceratopogonidae) midges. Having occurred mostly at latitudes below $40^{\circ} \mathrm{N}$ until 1998 , the disease has invaded southern and Mediterranean Europe in recent years (Baylis, 2002; Mellor and Wittmann, 2002). Invasion of this area has been linked to the northward spread of its main African vector Culicoides imicola and, beyond this vector's range, transmission by indigenous European Culicoides species. Areas where European Culicoides species (primarily the C. obsoletus complex and the C. pulicaris complex) are suspected of transmitting the disease include Italy (Caracappa et al., 2003; Goffredo and Meiswinkel, 2004; Torina et al., 2004; De Liberato et al., 2005), Bulgaria (Purse et al., 2006), Greece (Patakakis, 2004), the Balkan countries (Panagiotatos, 2004) and, in 2006, The Netherlands, Belgium, Germany and northern France (Thiry et al., 2006).

Culicoides biting midges are highly sensitive to weather conditions (Mellor et al., 2000; Wittmann and Baylis, 2000) and can be passively dispersed over long distances by prevailing winds (Sellers and Marouf, 1989, 1991; Sellers, 1992; Braverman and Chechik, 1996) leading to a rapid spread of the pathogens they carry. When characterizing the movements of insect vectors, Reynolds et al. (2006) distinguish between two types of behaviour, i.e. the 'vegetative' or short-distance movements directed towards resources required for growth and reproduction, and the straightened-out, generally longdistance, migratory movements. For Culicoides, in particular, Sellers (1992) similarly observed two types of flight:

(i) the short-distance flights that occur in any direction (both up- and downwind) at low or zero wind speeds; and

(ii) the long-distance dispersal (up to several $100 \mathrm{~km}$ ) which occurs when the midges are carried by winds with speeds exceeding what can be achieved by unaided flight.

The modern view is that these long-distance movements are not accidental on the part of the insect but instead actively initiated and maintained (reviewed in Reynolds et al., 2006). There are suggestions that the long-distance movements by Culicoides may be terminated not only when the wind drops (Sellers, 1992), but also by the influence of the topography of the terrain (Bishop et al., 2000, 2005) and even actively by the insect ceasing to move its wings which results in its landing even in strong winds. For this dispersal process to be of epidemiological importance, the midge must survive long enough after landing to replicate the virus to a transmissible level. In addition, it needs to find and bite a susceptible ruminant host, the probability of which is influenced by the local habitat, the weather conditions, the number of hosts at each destination, and the presence or absence of the virus at the source.

Measuring the movement rates of insects directly in the field is very difficult but the epidemiological importance of such movements is borne out by known incursions of bluetongue into new territories in the absence of known animal movements. Bishop et al. (2000) estimated the per-season colonization rate of vectors into an area seasonally free of C. brevitarsis midges next to a region with year-round populations. They looked at the rate and locations of the dispersal into the seasonally free area over several summers and related the dispersal to the speed and direction of the prevailing winds, weather conditions, and topography. The association between incursions and wind events has been qualitatively assessed by Sellers et al. (1978) and Sellers and Pedgley (1985) who examined wind events in relation to incursions of bluetongue in Cyprus, Turkey and Portugal. Using formal trajectory analysis, Alba et al. (2004) investigated the possibility of introduction of infected midges on the Balearic Islands from Sardinia during the 2000 outbreaks. They calculated backward wind trajectories for a limited number of days, i.e. those when the climatic conditions (humidity, temperature, wind) were considered to be highly appropriate for midge flight. Using this approach, they could match the Balearic outbreaks with previous outbreaks in Sardinia. This also showed that infected Culicoides could have been transported by wind from Sardinia to the Balearic Islands.

In this paper, we propose a standardised quantita- 
tive approach for the use of wind data in the analysis and risk assessment of bluetongue spread in the Mediterranean region. Confounding factors such as animal movement, herd distribution, and terrain topography were not taken into account but shall be included within this framework in the future.

\section{Material and methods}

Outbreak data from 1999 and 2001 for Greece and Bulgaria were obtained from the Institute of Animal Health (Pirbright, UK) which gives the date of confirmation for each outbreak studied. The outbreak sites had been georeferenced retrospectively by reference to websites detailing the co-ordinates of small villages in which farms were located using the Alexandria Digital Library Project of the University of California (Santa Barbara, CA, USA; http://www.alexandria.ucsb.edu) and the GEOnet Names Server, National Imagery and Mapping Agency (http://gnswww.nga.mil/geonames/GNS/ index.jsp). Serological and virological data concerning the serotypes of bluetongue circulating in each region were provided by the Hellenic Ministry of Agriculture in Greece and the Central Veterinary Research Institute in Bulgaria.

It must be taken into consideration that since bluetongue virus often circulates silently in diseaseresistant animals, the distribution of outbreaks can in reality be a vast underestimate of the real transmission status. For example, during the BTV-9 incursions in Bulgaria in 1999 and 2001, only between $0.1 \%$ and $2 \%$ of susceptible individuals in the herds became sick (Purse et al., 2006) which makes it likely that much transmission there went unrecorded. In Greece and Croatia, on the other hand, the BTV-9 strain was highly virulent (Listeš et al., 2004; Panagiotatos, 2004) causing severe clinical signs and high morbidity and mortality in sheep (Panagiotatos, 2004) which provides evidence supporting the likelihood that, in this case, most of the transmission was recorded. This is borne out by detection of transmission in sentinels inland in
Bulgaria, whilst recorded outbreaks are reported from the borders (Purse et al., 2006).

The European Centre for Medium-Range Weather Forecast (ECMWF) (www.ecmwf.int) has compiled the data from various meteorological institutes in order to produce and promote the use of a comprehensive set of global analyses describing the atmospheric and land and oceanic conditions during 45 years (from September 1957 until August 2002). Apart from this open source, data after the latter date are also available from the ECMWF archive, but have to be paid for. After compilation, the dataset was re-analyzed using several atmospheric models (Kållberg et al., 2004). From the ECMWF Re-Analysis 40-year archive (ERA-40) dataset, more than 60 different parameters can be extracted. The east and north components of the wind vectors ( $\mathrm{U}$ and $\mathrm{V}$, respectively) for the years 1999-2001, were extracted from the ERA-40 dataset at a spatial resolution of $0.5 \times 0.5$ degree latitude and longitude. These $\mathrm{U}$ and $\mathrm{V}$ components are measured every six hours (00h, 06h, $12 \mathrm{~h}$ and $18 \mathrm{~h}$ ) at four different pressure levels: 700, 850, 925 and $1000 \mathrm{hPa}$ which correspond to the approximate altitudes of $3000 \mathrm{~m}, 1450 \mathrm{~m}, 760 \mathrm{~m}$ and $100 \mathrm{~m}$ above ground level, respectively. Reynolds et al. (2006) suggest that nocturnal migrants might be concentrated in a $200-400 \mathrm{~m}$ belt above ground which agrees with the very few field findings so far for Culicoides (Chapman et al., 2004; Reynolds and Carpenter, unpublished data). On the other hand, even though this is not supported with empirical evidence, Alba et al. (2004) found that the pressure levels at altitudes, corresponding to pressure levels of 900 to $1000 \mathrm{hPa}$, matched well with the dispersal of Culicoides from Sardinia to the Balearic Islands.

The U and V components for each pressure level and time window were combined to determine the wind amplitude and wind direction (Eqs. 1-2):

$$
\begin{gathered}
\|\overrightarrow{\mathrm{V}}\|=\sqrt{u^{2}+v^{2}} \\
\|\alpha\|=\arctan \frac{v}{u}
\end{gathered}
$$


where $\|\vec{v}\|$ is the amplitude of the wind vector and $\alpha$ the angle of the wind vector. Based on these wind data, two-dimensional (2-D) horizontal trajectories were calculated. Supposing an air parcel is found at the location $\mathrm{P}_{0}$ at the time $\mathrm{t}_{0}$ and with the velocity vector $\vec{v}$, then the position of the parcel an interval later $(t+\Delta t)$ would be at $\mathrm{P}_{1}$ (given a constant velocity vector $\vec{v}$ ). Repeating this for a number of time intervals yields the trajectory for this particular air parcel. The accuracy of this computation depends on the time intervals chosen: the shorter they are, the more accurate the direction of the trajectory. The accuracy may also be improved by applying a second-order approach. Whilst the first order approach assumes a constant velocity over the whole passage studied, the second-order approach assumes constant acceleration. The change of the position of an air parcel over a very small time period $(\delta \mathrm{t})$ can be expressed by the so-called Taylor expansion:

$$
\vec{r}(t+\delta t)=\vec{r}(t)+\vec{r}^{\prime}(t) \delta t+\frac{1}{2 !} \vec{r}^{\prime \prime}(t) \delta t^{2}+\ldots
$$

where $\vec{r}$ is the position vector of the parcel and the prime symbolises the time derivatives.

Evidently, $\vec{r}^{\prime}(t)=\vec{v}(t)$ and $\vec{r}^{\prime \prime}(t)=\vec{v}^{\prime}(t)$. A simple integration yields:

$$
\vec{r}(t+\Delta t)=\vec{r}(t)+\vec{v}(t) \Delta t+\frac{1}{2} \vec{v}^{\prime}(t) \Delta t^{2}
$$

with

$$
\vec{v}^{\prime}(t) \approx \frac{\vec{v}(t+\Delta t)-\vec{v}(t)}{\Delta t}
$$

Introducing Eq. 5 into Eq. 4 yields the position vector at the time $t+\Delta t$ :

$$
\vec{r}(t+\Delta t)=\vec{r}(t)+\frac{\vec{v}(t+\Delta t)-\vec{v}(t)}{2} \Delta t
$$

Therefore, the elementary trajectories in this second-order approach were computed using an aver- age of the wind at the points $\mathrm{P}_{0}$ and $\mathrm{P}_{1}$, where the wind vector at $\mathrm{P}_{1}$ is assessed by a forward-backward iterative method.

The trajectories were calculated using a 2-D wind trajectory algorithm in a Grid Analysis and Display System (GrADS) (http://www.iges.org/grads/) starting from one week prior to the first outbreak case of the epidemic in question and lasting until one week after the end of the last outbreak case. In Greece, this was only carried out for sites with the known Greek serotype, while the actual outbreak sites were used for Bulgaria. Table 1 lists the serotypes per year and area.

The time window of one week was chosen because there is a time lag of this order of magnitude between the date of infection and the date of clinical diagnosis. This is due to the incubation period during which clinical signs have not yet developed and the delay before a suspected outbreak is actually confirmed by the local veterinary services. For each outbreak site, the infected midge vector can be transported as long as no vector control measures have been undertaken.

Therefore the trajectories were calculated until one week after the first outbreak date, after which disease control measures presumably would be in place. For example, in the 1999 outbreak in Greece the following measures were taken: on-thespot killing and destruction of sero-positive animals, the use of insect-repellents on all live animals, vector eradication in likely breeding sites, and prohibition of all contacts with other animals by confining the herds within the area of infection. Each vertex in the trajectory was stored and used to draw and overlay the trajectory with the outbreak data.

The temperature and relative humidity profiles derived from ECMWF for the selected days were visually inspected with regard to the available pressure levels. From this followed that at the pressure level of $700 \mathrm{hPa}$, the temperature was consistently lower than $280 \mathrm{~K}\left(8^{\circ} \mathrm{C}\right)$, while the relative humidity varied between $25 \%$ and $50 \%$. The combination of low temperature and low humidity made it unlikely that Culicoides would be trans- 
Table 1. Serotype of bluetongue per year and per region used for trajectory modelling.

\begin{tabular}{lccl}
\hline Year & Serotype & Virus (v)/serology $(\mathrm{s})$ & Region \\
\hline 1999 & 9 & $\mathrm{~s}$ & Bourgas, Yambol, Kardjali \\
& 9 & $\mathrm{v}$ & Rodopi \\
& 4 & $\mathrm{v}$ & Evros, Chalkidiki, Piera, Evia, Magnesia, Lesvos \\
& 16 & $\mathrm{v}$ & Rhodes \\
2001 & 1 & $\mathrm{v}$ & Ionnina \\
& 9 & $\mathrm{~s}$ & Ionnina \\
\hline
\end{tabular}

ported at this pressure level. The temperature and the relative humidity at the other pressure levels were within the optimal range for Culicoides species $\left(288-300 \mathrm{~K}\right.$, i.e. $16-28^{\circ} \mathrm{C}$, and $40-70 \%$ ). This is supported by Reynolds et al. (2006) who mention that migrating insects are largely confined to the lowest $2 \mathrm{~km}$ of the atmosphere, with higher flights (up to $3 \mathrm{~km}$ ) only under certain circumstances. This altitude range largely coincides with the atmospheric (or planetary) boundary layer (ABL) (reviewed in Reynolds et al., 2006) within which the air is directly affected by the sun's heating of the Earth surface, and by the friction due to surface roughness. The other pressure levels were also calculated but because the preliminary results of these calculations (not shown here) indicated that, up to a distance of $250 \mathrm{~km}$, there were few differences between the trajectories drawn for the other three pressure levels, only the $850 \mathrm{hPa}$ level was further investigated.

Even though the insects under study are most active at sunrise and sunset it was decided to model the forward trajectories at noon given that the upward thermal vortices are the strongest at the end of the morning, i.e. the most likely time for the midges to be transported in an upward direction (Gatehouse, 1997). Next to light variations, insect activity is triggered by changing weather conditions such as temperature, wind and rainfall. After calculating all trajectories, unsuitable trajectories were filtered out by eliminating those with a wind speed below $3 \mathrm{~m} / \mathrm{s}$ and above $11 \mathrm{~m} / \mathrm{s}$. Below this threshold, the midges exhibit active movement irrespective of wind direction, whilst they prefer to shelter at higher wind speeds (Bowden and Gibbs, 1973; Wittmann and Baylis, 2000).

\section{Results}

The 1999 BTV-9 outbreak in Bulgaria and Greece

The 1999 BTV-9 epidemic started in south-eastern Bulgaria near the Black Sea coast. It spread westwards from June to August, thus covering a distance of $250 \mathrm{~km}$ in less than three months. In Greece, the first cases were recorded in Rodopi, a prefecture at the Greek border with Bulgaria. From there it spread along the border with Bulgaria, as well as to the south towards the prefecture of Evia.

The very first cases were found in the villages of Slivarovo and Belevren (Bulgaria) almost at the border with Turkey at the end of June (Fig. 1a). Possible routes of wind-borne introduction were assessed using backward trajectories (blue arrows) which show possible incursions either from the north of Bulgaria or from the east (Turkey). During the first two weeks of July the next cases appeared northwards in the province of Bourgas (Bulgaria) near the Black Sea. During the same period, the first Turkish cases were reported in the province of Edirne (Ertürk et al., 2004), west of the Bourgas province. During the second half of July, the epidemic further spread south-westwards over the provinces of Yambol and Haskovo in Bulgaria. Forward wind trajectories (black arrows) were computed from the villages of Slivarovo and Belevren (Fig. 1a). A limited number of trajectories pointed in a north-west direction, whilst the majority pointed south-west into Turkey.

In August (Fig. 1b), BTV-9 outbreaks appeared in the province of Kardjali (Bulgaria) and in the prefecture of Rodopi in Greece. In Greece, the evidence was generally serological without isolation of the causative virus (BTV-9 was only isolated from two 


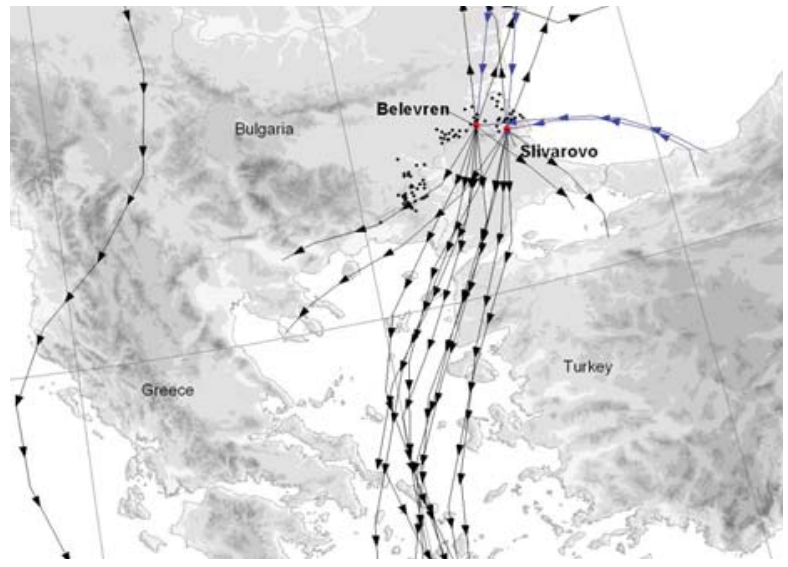

Fig. 1. (a) Blue trajectories show 1999 BTV-9 backward trajectories to Slivarovo and Belevren (introduction). Black trajectories show 1999 BTV-9 forward trajectories from Slivarovo and Belevren. Red dots are outbreaks recorded in June, black dots are all cases of BTV-9.

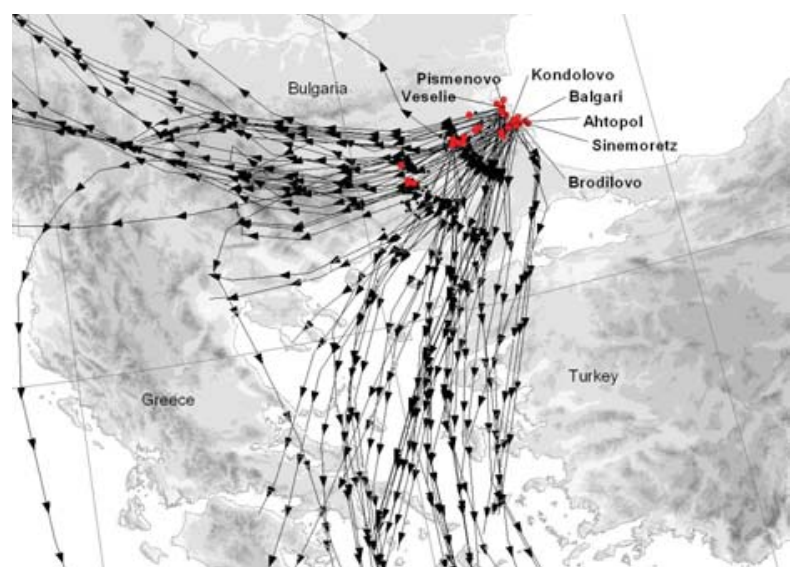

Fig. 1. (b) Black trajectories show 1999 BTV 9 forward trajectories from Veselie, Pismenovo, Balgari, Kondolovo, Brodilovo, Sinemoretz and Athopol (July). Red dots are outbreaks recorded in July, black dots are all cases of BTV-9.

sites). Forward trajectories (black arrows) were computed from the villages of Veselie, Pismenovo, Balgari, Kondolovo, Brodilovo, Sinemoretz and Athopol in Bulgaria, all of which had outbreaks during the first two weeks of July. Two general directions were observed (Fig. 1b): a first group of trajectories blowing inland from Bulgaria towards Greece and a second group going from Bulgaria across Turkey and the Aegean Sea.

\section{The 1999 BTV-4 outbreak in Greece}

Two separate BTV-4 epidemics were reported in Greece in 1999. A first incursion was detected in Evros in August 1999 in the villages of Pendalofos and Mandra. One week later it struck in Kato Kambi and Keresia (Fig. 2a). In order to assess the route of introduction of the disease, backward trajectories (blue arrows) were computed. The main winds were found to have been blowing either from Bulgaria in the north towards the Evros prefecture, or from the north-east from the Anatolian provinces of Edirne and Kirklareli. From Pendalofos and Mandra, forward trajectories (black arrows) were determined, and the wind was then seen to be of a mainly southwesterly direction blowing across the Aegean Sea towards the island of Thasos (prefecture of Kavala) and the islands of Samothriaki (Evros) and Limnos (Lesvos). The wind bundle further continued towards the prefectures of Magnesia and Evia.

The next cluster of cases was found around Gomati in the prefecture of Chalkidiki in September (Fig. 2b). The forward trajectories (black arrows in Fig. 2a), coming from the villages in Evros just missed Gomati, while the backward trajectories (blue arrows in Fig. 2b) show that the wind arriving

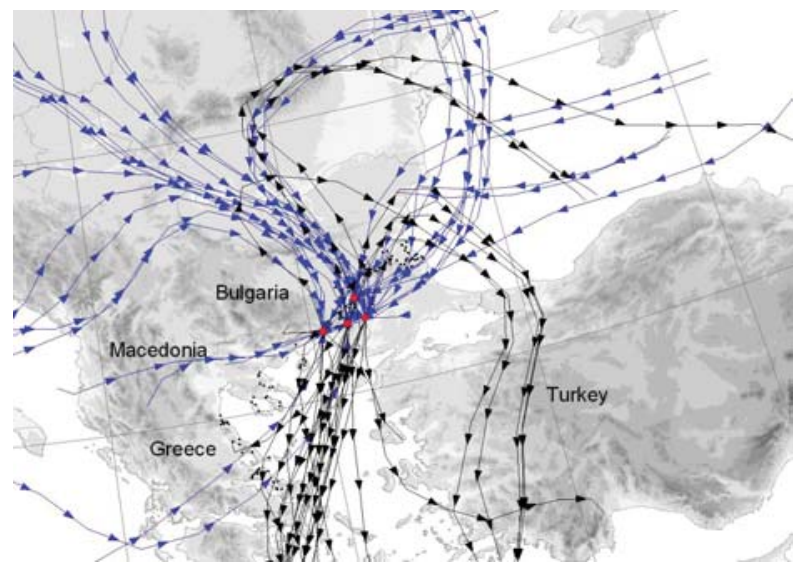

Fig. 2. (a) Blue trajectories show 1999 BTV-4 backward trajectories to Pendolofos, Mandra, Kato Kambi and Keresia (introduction). Black trajectories show 1999 BTV-4 forward trajectories from Pendolofos, Mandra, Kato Kambi and Keresia. Red dots are cases used for trajectory calculation, black dots are all cases of BTV-4. 


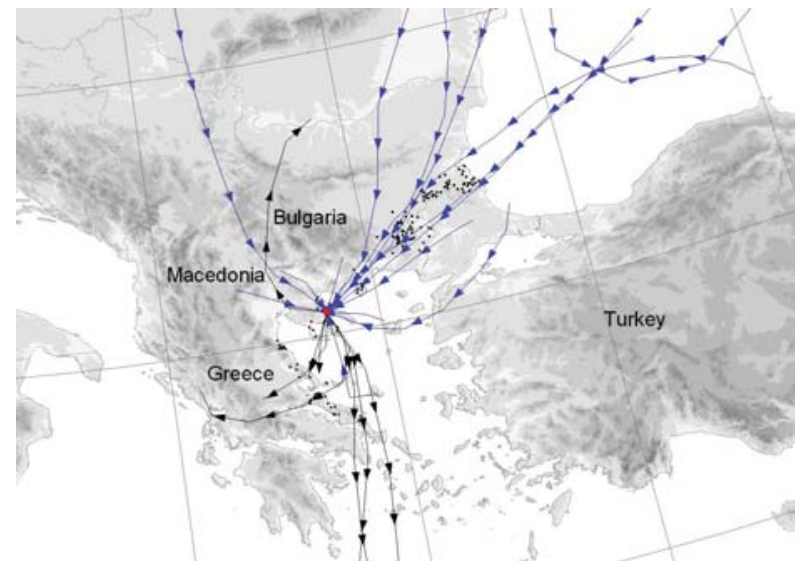

Fig. 2. (b) Blue trajectories show 1999 BTV-4 backward trajectories to Gomati. Black trajectories show 1999 BTV-4 forward trajectories from Gomati. Red dots are cases used for trajectory calculation in September, black dots are all cases of BTV-4.

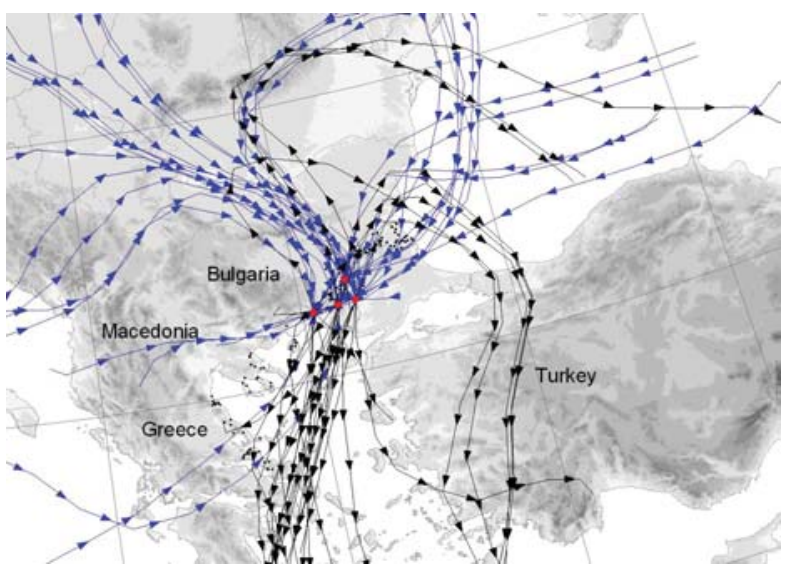

Fig. 2. (c) Blue trajectories show 1999 BTV-4 backward trajectories to N Poroi, Skiathos, Psakhna. Black trajectories show 1999 BTV-4 forward trajectories from N Poroi, Skiathos, Psakhna. Red dots are cases used for trajectory calculation in October and November, black dots are all cases of BTV-4.

at Gomati could indeed be traced back towards Evros. The forward trajectories (black arrows) determined from Gomati indicate that Evia and Magnesia were at risk. Backward trajectories determined from $\mathrm{N}$ Poroi (Fig. 2c, blue arrows), in the prefecture of Piera, show that there was no consistent wind pattern for this particular point and the same was true for the forward trajectories. In the final stage
(Fig. 2c), trajectories for the villages Skiathos (Magnesia) and Psakhna (Evia) were determined. Most of these trajectories pointed south while some others headed east towards Khios, where outbreaks were previously recorded (in September).

A second incursion was reported from the isle of Lesvos (Fig. 3). The first outbreak started in the beginning of September and the epidemic continued until December. Backward trajectories (blue arrows) were computed to verify the hypothesis that the outbreaks could have been initiated by the incursion of BTV4-infected midges from the Anatolian provinces in Turkey. The backward wind trajectories from Andissa showed that the wind was blowing, either from the two Anatolian provinces Edirne and Kirklareli or from the Black Sea across the province of Istanbul.

\section{The 1999 BTV-16 outbreak in Greece}

A third BTV serotype, BTV-16 (Panagiotatos, 2004), was found on the island of Rhodes in September. The first case was recorded in Petaloudes and the epidemic continued until the beginning of November (12 outbreaks in total). Backward trajectories (blue arrows) were calculated in order to determine possible routes of incursion by BTV-16infected midges (Fig. 4). The trajectories were calculated from the villages of Archangelos, Ataviros,

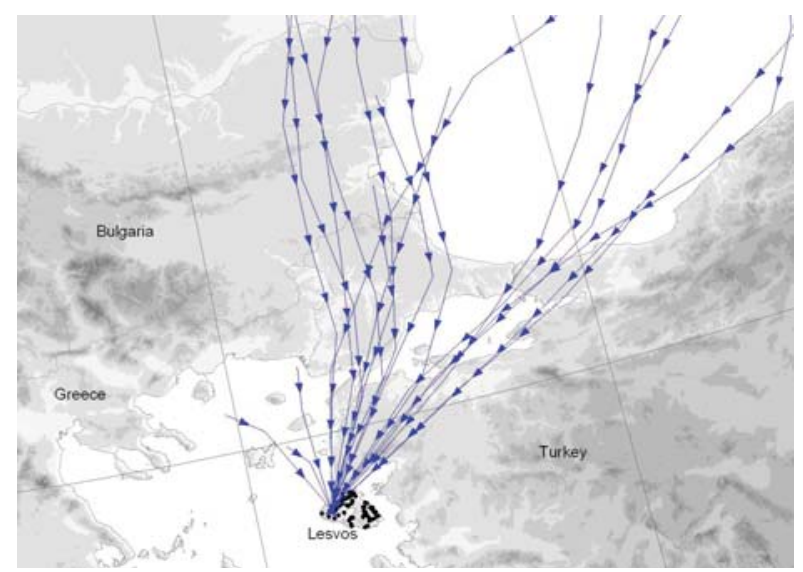

Fig. 3. Blue trajectories show 1999 BTV-4 backward trajectories to Lesvos. 


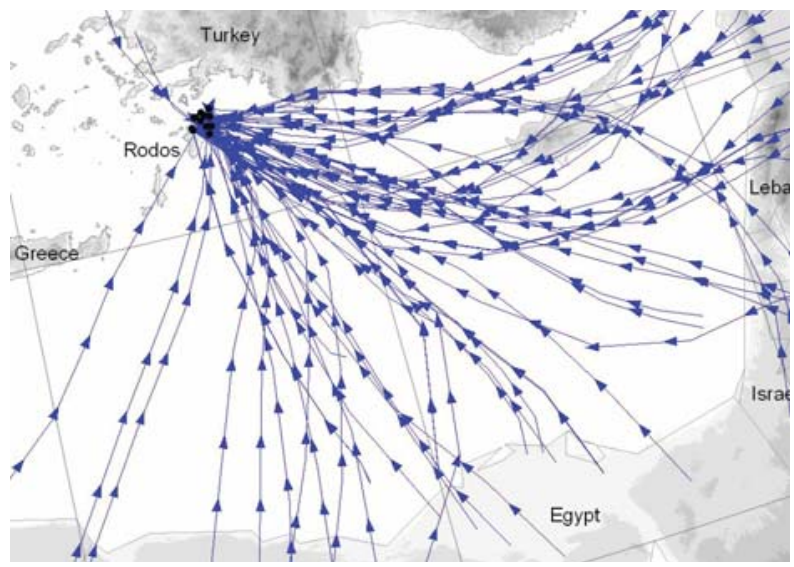

Fig. 4. Blue trajectories show 1999 BTV-16 backward trajectories to Ialisos, Petaloudes, Afandou, Kamiros, Embonas, Ataviros, Lindia and Archangelos on the island of Rodos (Greece).

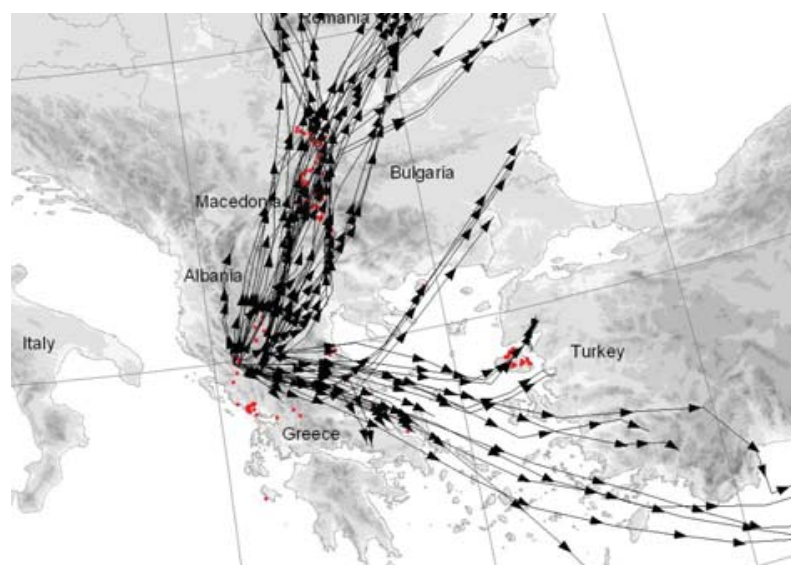

Fig. 5. Blue trajectories show 2001 BTV-9 backward trajectories to Vasilika from Italy. Black trajectories show 2001 BTV-9 forward trajectories from Smixi, Vissani, Faraggi, Miliotades and Karyes and BTV-9/1 forward trajectories from Fariggi and Karyes.

Embonas, Lindia, Afandou and Petaloudes (Fig. 3). All computed trajectories were seen originating from North Africa (Libya, Egypt) and the MiddleEast (Israel, Lebanon, Syria).

The BTV-16 virus strain was also isolated in two other sites, i.e. Ierossos (Chalkidiki) and Kerasia (Rodopi) which are situated away from the island of Rhodes. For both these sites, backward trajectories (not shown here) indicated that the wind was coming from the north.
The 2001 BTV-1/9 outbreak in Greece and Balkan region

In Greece and the Balkans, two serotypes, i.e. serotype BTV-9 and serotype BTV-1 (Panagiotatos, 2004), were circulating simultaneously in 2001. This was the first time an epidemic with BTV1 had been confirmed in Europe. Virus isolation showed that the BTV-1 strain was more widespread than the BTV-9 strain for which only serological evidence was found. In contrast to the 1999 epidemics, the BTV epidemic of 2001 spread from east to west, starting off the west coast of Greece in the beginning of September after which it spread to Albania, Macedonia, Bulgaria, Kosovo and Croatia covering a distance of $700 \mathrm{~km}$. The first outbreaks occurred in the prefecture of Ioannina. In this prefecture, virus isolation revealed the presence of BTV-1, while the serological data indicated a concurrent presence of BTV-9.

Forward trajectories (Fig. 5, black arrows) were calculated starting from the villages where the first outbreaks were detected on September 9, 2001. Two major directions of possible wind-borne spread of infected midges were observed. The first group pointed north covering the prefecture of Kastoria and then crossing into Bulgaria via Albania and Macedonia. The second group pointed east covering the other infected prefectures, i.e. Trikila, Larissa, Magnesia and Euboea. This group ultimately reached the islands of Rhodes and Lesvos.

\section{Discussion}

\section{ECMWF data versus meteorological data}

Until now, ground station data have been the prime source for modelling the spread of Culicoides by wind (Bishop, 2000; Alba et al., 2004). The two main advantages of using ECMWF gridded data are:

(i) the possibility to assess trans-boundary spread of diseases without having to collate and com- 
bine data from various meteorological institutes manually; and

(ii) the continual availability, at standardised time intervals, of contemporary and archived data.

In addition, the spatial latitude/longitude resolution of $0.5 \times 0.5$ degrees is often similar to, in some cases better than, datasets obtained by interpolation of data measured on the ground. The accuracy of the ECMWF data is reliable because the dataset is assembled from the national institutes, improved with data from other sources such as remote sensing and finally fed into a calibrated atmospheric model to improve the original predictions. Because this atmospheric model is used, it also becomes possible to model the spread of vectors at different pressure levels, which is important for long-distance dispersal over land.

Data can be downloaded from the ECMWF archive and are distributed in GRIB-format. Whilst this format is commonly used by meteorologists, it is not recognised by GIS Software. However, the data can be processed using GrADS but this requires a Linux/Unix operating system or the availability of a Cygwin installation running on Windows.

\section{The 1999 BTV-9 outbreak in Bulgaria and Greece}

The first outbreaks of BTV-9 in Bulgaria were detected at the end of June 1999 in the villages of Slivarovo and Belevren (Fig. 1a). The first route of introduction to these villages, close to the Turkish border, is hard to assess. No previous outbreaks had been reported, either in Bulgaria or in Turkey. From this point on, however, we see that the spread of infected midges up to the north in Bourgas (Bulgaria) and to the east into Turkey is possible given the prevailing wind patterns (in black). A limited number of wind trajectories pointed to the west where outbreaks were found two weeks later. If the number of forward wind events towards the west of Bourgas is not sufficient to explain the new outbreaks all by itself, a secondary route of introduction might have been transport of infected animals towards that region.
On the other hand, a very dense cloud of backward wind trajectories covered the provinces of Edirne and Kirklareli in Turkey, where the first Turkish outbreaks were found at the end of July (Ertürk et al., 2004). This supports the hypothesis formulated by Panagiotatos (2004) stating that the outbreaks in Turkey originated in Bulgaria and were simply detected later in the season.

During the secondary stage of the epidemic in Bulgaria (Fig. 1b), the prevailing winds moved west/south-west across Bulgaria to Greece and southern Turkey. The new outbreaks were found in the provinces of Yambol, Haskovo, and Kardjali as well as in the Greek prefecture of Rodopi. All these provinces were directly beneath the prevailing forward wind trajectories in Bulgaria.

Even though the wind patterns show that a possible spread of infected midges by wind to the west inland is possible, outbreaks were not found. However, as stated earlier, the disease could have been circulating in this area without detection because of its low morbidity. This might be explained by the topography which changes from flat to mountainous with peaks exceeding $2000 \mathrm{~m}$. Bishop et al. (2000) found that, rather than along the trajectories, the vectors were found in greater abundance at the bottom of the Great Dividing Range, a mountain range in New South Wales (Australia). The fact that no outbreaks were found in these mountain areas might be due to lack of suitable habitats for the midges or lack of suitable hosts. The former is unlikely, since Torina et al. (2004) recorded both the C. obsoletus complex and the C. pulicaris complex regularly at altitudes above $1200 \mathrm{~m}$. The same topographical change exists in the south in the Rodopi Mountains but the valley of the Ardas River possibly enabled the spread of the vector in this direction. The Ardas River whose source lies in the Rodopi Mountains near Smolyan, flows eastwards past Kardjali and Ivaylovgrad through the north of the Greek prefecture of Evros. Many wind trajectories were blowing along this direction at the time thus enabling the spread of the vector towards the prefectures at 
the Bulgarian border. Because topography plays an important role, future work should integrate topography and wind events within the same modelling framework.

\section{BTV-4 outbreak in Greece}

Concurrent to the outbreak of BTV-9, a secondary epidemic started in the province of Evros in Greece, which is bordering Turkey (Fig. 2a). According to Panagiotatos (2004), the Turkish government responded to the BTV outbreaks in July by mass vaccination with a mono-valent BTV-4 vaccine because the Turkish epidemics of the 1970s were caused by BTV-4. However, at a later stage, BTV-9 was identified as the cause of these recorded outbreaks. Since onward transmission of vaccine strains has been detected in the field for other BTV-vaccine strains, e.g. in Italy (Ferrari et al., 2005), Panagiotatos (2004) suspected that the BTV4 outbreaks in Greece were related to those in Turkey. This is likely given the backward wind trajectories coming from the northeast (Fig. 2b). However, Maan et al. (2004) mention that based on sequence comparisons the Turkish vaccine strain was not the cause of the European outbreak.

The Greek island of Lesvos showed BTV-4 outbreaks in September. Mellor and Wittmann (2002) suggested introduction from the east, which was deemed to be confirmed by the wind trajectories (Fig. 3).

\section{BTV-16 outbreak in Greece}

On the island of Rhodes BTV-16 was found to be responsible for the outbreaks across the island. Mellor and Wittmann (2002) assumed that the incursion of BTV-16 midges into Rhodes may have originated from the south. BTV-16 caused a major outbreak in Israel in 1993/94. Therefore, a pentavalent live attenuated vaccine (BTV-2, 4, 6, 10, 16) is disseminated on a voluntary basis to susceptible, non-pregnant sheep since 1995 (Shimshony, 2004). All the backward trajectories were traced back over- seas and many of them originated in Israel. This means that wind-borne spread of the infected vector from Israel to Rhodes is a likely route of introduction. It follows, from Savini et al. (2004) and Potgieter et al. (2005), that the BTV-16 strain found in Italy is indistinguishable from the live attenuated vaccine used in Israel (100\% homology). Nomikou et al. (unpublished data) showed that, based on segment 3/VP3, all the BTV-16 strains found in Greece, Turkey, Italy, Cyprus, Israel, Indonesia, India and Australia have a common Eastern origin, while BTV16 from Nigeria and Zimbabwe have an Western origin. This makes it likely that the Greek BTV-16 also originates from Israel, either from the live-attenuated vaccine or from a wild type. The introduction of BTV-16 to Chalkidiki and Rodopi, on the other hand, cannot be explained on the basis of wind trajectories. One possible source of introduction might be transport of infected animals or that winds at a different pressure level were responsible for the introduction of infected midges.

\section{BTV-1/9 outbreak in Greece and Balkan region}

The winds in the period of outbreaks in 2001 were predominantly blowing northwards (Fig. 5). This is consistent with the pattern of outbreak dates in both Greece and Bulgaria and also with the OIE reports of outbreaks in other areas (OIE, 2001a-f). Based on the serological evidence in Greece, these outbreaks were caused by BTV-9. Mellor and Wittmann (2002) and Panagiotatos (2004) mentioned that one month after the outbreaks in Greece, Macedonia also experienced bluetongue outbreaks. The serotype was not identified but was (and continues to be) suspected to be the BTV-9 strain. This is consistent with the wind patterns studied in this work which shows the wind to have been blowing steadily for a long period from Greece to Bulgaria, thereby crossing Macedonia (Fig. 5). The three major sources of the Macedonian outbreaks are all located downwind from the sources in Greece. In the OIE reports the suspected first date for 
Macedonia is not mentioned and there might have been a considerable time lag between the date of introduction and the date of detection. Panagiotatos (2004) mentions that neighbouring countries started to report the disease only after the alert in Greece. In the Former Yugoslav Republic of Macedonia bluetongue was suspected from September but outbreaks were reported in October. In most other neighbouring countries within the same outbreak period the serotype was not identified with the exception of the Former Republic of Yugoslavia where it was identified as BTV-9. However, outbreak data for these countries must be analyzed before making further assumptions on the windborne spread of bluetongue.

Panagiotatos (2004) postulated that the spread of infected midges towards Lesvos was limited by topography. Some of the trajectories were found to cross the island towards the Magnesia prefecture (Fig. 5). These trajectories covered the infected prefectures of Trikala, Larissa, Magnesia and Euboea. The further overseas spread from Euboea towards Lesvos would then be possible. Given the backward trajectories, another route might have been from Turkey were there was an outbreak of BTV-9 simultaneously (Ertürk et al., 2004) (not shown here).

The introduction of the epidemic in Greece on the east coast was assessed using backward trajectories, but the analysis was confounded by two factors. Firstly, none of the neighbouring countries found BTV-1 during the epidemic and, secondly, BTV-1 and BTV-9 are intermingled within Greece and not always diagnosed. Thus outbreaks cannot be directly associated with one serotype or the other. There is also the high probability that since its introduction to mainland Greece and Bulgaria in 1999, BTV9 may have over-wintered across large areas of the Balkans, either in infected midges or inside the mammalian host (Purse et al., 2006). In this case, neither wind-borne introduction of infected midges from Turkey or the Middle East nor movement of infected hosts would explain the pattern of arrival and spread in later years. Nevertheless, backward trajectories (not shown here) suggest the possible introduction of midges infected with BTV-9 by wind into Greece from the Italian provinces of Calabria and Puglia. In Calabria, outbreaks caused by BTV-9 started in June and continued until December, whilst in Greece, the first outbreaks appeared in September. During the week prior to the first Greek outbreaks, several trajectories could be traced back to the Italian peninsula. Maan et al. (2004) showed, using molecular evidence, that the BTV-1/9/16 isolates from Greece are more closely related to a group of eastern BTV-1 strains, particularly those from India, indicating that it may have eastern origins; however they did not include any Italian BTV-9 virus into their analysis. Nikolakaki et al. (2004) showed that, based on molecular evidence, the BTV9 isolates from Greece and Italy have a 99\% homology. In addition, they mention that recent isolates from Italy were almost identical suggesting a spread from a common source. Most authors, including Nikolakaki et al. (2004), assume, given that BTV-9 has an origin in Asia, that it spread from Greece to Bulgaria. This might have been possible during the outbreak in Greece in 2000 and vice versa in the following year.

\section{Conclusions}

Whilst other routes of introduction and/or dispersal such as transport of infected animals should always be taken into consideration, though these data are rarely widely available, the results discussed in this paper show that wind patterns derived from the ECMWF match well with the patterns of long-range spread of Culicoides-borne diseases both over land and sea for the strains of BTV in outbreaks under study. The observed wind patterns fit with the overall time/space sequence of these epidemics. The use of forward trajectories may serve to assess regions at risk of incursion of infected vectors from a known outbreak zone. As soon as an outbreak is reported, wind data from the days prior to this outbreak, with an appropriate delay that accounts for the incubation period of the pathogen and the delay in reporting of 
symptoms, can be used to calculate forward trajectories earmarking regions at risk. The time lag of several weeks observed here for long-range spread makes it possible to consider appropriate measures of control. Backward trajectories, on the other hand, can be useful for the assessment of possible routes of incursion into a previously uninfected region. Whilst the proposed approach needs further refining to improve its predictive force and to enable operational applications, currently ongoing with data from the BTV-8 epidemic in The Netherlands, Belgium, Germany and France, it is proposed as a first step towards a regional risk assessment tool.

\section{Acknowledgements}

The first author wants to acknowledge the input from Ana Alba at the onset of the project. This work was funded by Belgian Science Policy (Contract N ${ }^{\circ}$ 09/33).

Kiki Nomikou, Olga Mangana, Georg Georgiev, and Bethan V. Purse were supported by the European Commission Contract No. QLK2-2000-00611 ('Bluetongue \& other Culicoides-borne diseases threatening the EU: Identification of vulnerable areas by surveillance \& GIS modelling to aid risk assessment').

\section{References}

Alba A, Casal J, Domingo M, 2004. Possible introduction of bluetongue into the Balearic Islands, Spain, in 2000, via air streams. Vet Rec 155, 460-461.

Baker RHA, Guillet P, Sékétéli A, Poudiougo P, Boakye D, Wilson MD, Bissan Y, 1990. Progress in controlling the reinvasion of windborne vectors into the western area of the onchocerciasis control program in West Africa. Philos Trans R Soc Lond B Biol Sci 328, 731-750.

Baylis M, 2002. The re-emergence of Bluetongue. Vet J 154, 5-6.

Bishop AL, Barchia IM, Spohr A, 2000. Models for the dispersal in Australia of the arbovirus vector, Culicoides brevitarsis Kieffer (Diptera: Ceratopogonidae). Prev Vet Med 47, 243-254.

Bishop AL, Spohr LJ, Barchia IMM, 2005. Effects of altitude, distance and waves of movement of Culicoides brevitarsis Kieffer (Diptera, Cerotopogonidae). Prev Vet Med 65, 135-145.

Bowden J, Gibbs DS, 1973. Light-trap and suction trap catches of insects in the northern Gezira, Sudan in the sea- son of south ward movement of the intertropical front. Bull Entomol Res 62, 571-596.

Braverman Y, Chechik F, 1996. Air streams and the introduction of animal diseases borne on Culicoides (Diptera, Ceratopogonidae) into Israel. Rev Sci Tech 15, 1037-1052. Caracappa S, Torina A, Guercio A, Vitale F, Calabro A, Purpari G, Ferrantelli V, Vitale M, Mellor PS, 2003. Identification of a novel bluetongue virus vector species of Culicoides in Sicily. Vet Rec 153, 71-74.

Chapman JW, Reynolds DR, Smith AD, Woiwod IP, 2004. An aerial netting study of insects migrating at high altitude over England. Bull Entomol Res 94, 123-136.

De Liberato C, Scavia G, Lorenzetti R, Scaramozzino P, Amaddeo D, Cardeti G, Scicluna M, Ferrari G, Autorino GL, 2005. Identification of Culicoides obsoletus (Diptera: Ceratopogonidae) as a vector of bluetongue virus in central Italy. Vet Rec 156, 301-304.

Ertürk A, Tatar N, Kabakli O, Incoglu S, Cizmeci SG, Barut FM, 2004. The current situation of bluetongue in Turkey. Vet Ital 40, 137- 141.

Ferrari G, De Liberato C, Scavia G, Lorenzetti R, Zini M, Farina F, Magliano A, Cardeti G, Scholl F, Guidoni M, Scicluna MT, Amaddeo D, Scaramozzino P, Autorino GL, 2005. Active circulation of bluetongue vaccine virus serotype- 2 among unvaccinated cattle in central Italy. Prev Vet Med 68, 103-113.

Gatehouse AG, 1997. Behavior and ecological genetics of wind-borne migration by insects. Annu Rev Entomol 42, 475-502.

Goffredo M, Meiswinkel R, 2004. Entomological surveillance of bluetongue in Italy: methods of capture, catch analysis and identification of Culicoides biting midges. Vet Ital 40, 260-266.

Kållberg P, Simmons A, Uppala S, Fentes M, 2004. The ERA40 archive. ERA-40 project Report Series. Reading: ECMWF, $31 \mathrm{p}$.

Listeš E, Bosnić S, Benić M, Lojkić M, Cac Z, Cvetnić Z, Madić J, Šeparović S, Labrović A, Savini G, Goffredo M, 2004. Serological evidence of bluetongue and a preliminary entomological study in southern Croatia. Vet Ital 40, 221-225.

Maan S, Samuel AR, Maan NS, Attoui H, Rao S, Mertens PPC, 2004. Molecular epidemiology of bluetongue viruses from disease outbreaks in the Mediterranean Basin. Vet Ital 40, 489-497.

Mellor PS, Boorman J, Baylis M, 2000. Culicoides biting midges: their role as arbovirus vectors. Annu Rev Entomol 45, 307-340.

Mellor PS, Wittmann EJ, 2002. Bluetongue virus in the Mediterranean Basin 1998-2001. Vet J 164, 20-37.

Nikolakaki SV, Nomikou K, Magana-Vougiouka O, Papanastassopoulou M, Koumbati M, Papadopoulos O, 2004. S10 segment sequence analysis of some Greek bluetongue virus strains. Vet Ital 40, 468-473.

OIE, 2001a. Disease information 14 (38), 215 p.

OIE, 2001b. Disease information 14(39), 223 p. 
OIE, 2001c. Disease information 14(40), 230 p.

OIE, 2001d. Disease information 14(41), 234 and 242 pp.

OIE, 2001e. Disease information 14(45), 237, 257, 262, 265 pp.

OIE, 2001f. Disease information 14(48), 280 p.

Panagiotatos DE, 2004. Regional overview of bluetongue viruses, vectors, surveillance and unique features in Eastern Europe between 1998-2003. Vet Ital 40, 61-73.

Patakakis MJ, 2004. Culicoides imicola in Greece. In: Bluetongue, Pt 1, Proceedings (MacLachlan NJ and Pearson JE eds) 40, 232-234.

Potgieter AC, Monaco F, Mangana O, Nomikou K, Yadin H, Savini G, 2005. VP2-segment sequence analysis of some isolates of bluetongue virus recovered in the mediterranean basin during the 1998-2003 outbreak. J Vet Med 52, 372-379.

Purse BV, Nedelchev N, Georgiev G, Veleva E, Boorman J, Denison E, Veronesi E, Carpenter S, Baylis M, Mellor PS, 2006. Spatial and temporal distribution of bluetongue and its Culicoides vectors in Bulgaria. Med Vet Entomol 20, 335-344.

Reynolds DR, Chapman JW, Harrington R, 2006. The migration of insect vectors of plant and animal viruses. Adv Virus Res 67, 453-517.

Ritchie SA, Rochester W, 2001. Wind-blown mosquitoes and introduction of Japanese encephalitis into Australia. Emerg Infect Dis 7, 900-903.

Savini G, Potgieter AC, Monaco F, Mangana-Vougiouka O, Nomikou K, Yadin H, Caporale V, 2004. VP2 gene sequence analysis of some isolates of bluetongue virus recovered in the Mediterranean Basin during the 1998-2002 outbreak. Vet Ital 40, 473-479.

Sellers RF, 1992. Weather, Culicoides, and the distribution and spread of bluetongue and African horse sickness viruses. In: Walton TE, Osburn BI, eds, 1992. Bluetongue, African horse sickness, and related arbiviruses. Boca Raton, FL, CRC, 1042 pp.

Sellers RF, Maarouf AR, 1989. Trajectory analysis and bluetongue virus serotype 2 in Florida 1982. Can J Vet Res 53, 100-102.

Sellers RF, Maarouf AR, 1991. Possible introduction of epizootic hemorrhagic disease of deer virus (serotype 2) and bluetongue virus (serotype 11) into British Columbia in 1987 and 1988 by infected Culicoides carried on the wind. Can J Vet Res 55, 367-370.

Sellers RF, Pedgley DE, 1985. Possible windborne spread to western Turkey of bluetongue virus in 1977 and of Akabane virus in 1979. J Hyg (Lond) 95, 149-158.

Sellers RF, Pedgley DE, Tucker MR, 1978. Possible windborne spread of bluetongue to Portugal, June-July 1956. J Hyg (Lond) 81, 189-196.

Shimshony A, 2004. Bluetongue in Israel - a brief historic overview. Vet Ital 40, 108-116.

Thiry E, Saegerman C, Guyot H, Kirten P, Losson B, Rollin F, Bodmer M, Czaplicki G, Toussaint JF, De Clerq K, Dochy JM, Dufey J, Gilleman JL, 2006. Bluetongue in northern Europe. Vet Rec 159, 327.

Torina A, Caracappa S, Mellor PS, Baylis M, Purse BV, 2004. Spatial distribution of bluetongue virus and its Culicoides vectors in Sicily. Med Vet Entomol 18, 81-89.

Wittmann EJ, Baylis M, 2000. Climate change: effects on Culicoides-transmitted viruses and implications for the UK. Vet J 160, 107-117. 